\title{
Being There: International Studio Pedagogy in the Post-Digital City
}

\author{
IGOR SIDDIQUI \\ The University of Texas at Austin
}

\begin{abstract}
The relationship between architecture and the city is explored through the teaching of an international, travelbased studio, a collaboration between the University of Texas at Austin and the École Nationale Supérieure d'Architecture de Paris-Belleville. The notion of the post-digital is primarily explored through the aspiration of post-spectacle in architecture. The paper captures a preoccupation with 'being there' not as a dogmatic stricture nor a nostalgic retreat to a fantasy of a pre-digital reality, but rather as a sense that physical presence - in learning, in design, in our making and experiencing of buildings and cities - is indeed, undeniably, worth something. The studio teaching discussed in this paper actively explores this value in the making of architecture in relation to the city. Specifically, the paper focuses on (1) studio as a model for practice, (2) developed mechanisms for studio collaboration and exchange, (3) urban construct of the block as a framework, (4) use of housing as design prompt, and (5) working methods of the studio as reflections of core disciplinary knowledge.
\end{abstract}

The last blow to the society of the spectacle was $9 / 11$ when reality overtook media. We could never make a science fiction film like that. When reality overtook media, you realize that being in New York near the event, the Heideggerian notion of being there, became more important than seeing it on media. For me, being there re-established architecture and urbanism as an important condition of culture as we move forward.

-Peter Eisenman, "Thoughts on the World Trade Center"

\section{INTRODUCTION}

Guy Debord and Martin Heidegger make unlikely bedfellows, especially in a bed made by Peter Eisenman. Over a decade since the statement that would momentarily bring these two figures together was made by Eisenman, the declaration of the end of the society of the spectacle easily passes as an overstatement and the brief flash of Heidegger can be potentially forgotten as an anachronistic glitch. Yet the statement arguably resonates even more strongly today, especially as one considers the relationship between architecture and urbanism in the post-digital realm. So while neither one of Eisenman's philosophical references may call for an urgent dive into its deep ideological provenance, they both help him outline two salient points about (1) being somewhere as more important than seeing it in the media, and (2) the importance of architecture and urbanism moving forward.
These points may be seen as convictions, speculations, aspirations, or values - as instrumentalities for the projective practice of design.

In the context of this paper, Eisenman's points are taken as prompts for reflecting upon and further articulating a pedagogy of an architecture studio. The relationship between architecture and the city is explored through the teaching of an international, travel-based collaborative studio; the notion of the post-digital is in this case thought of as post-spectacle, not as a fully formed reality but as a necessary aspiration for architecture. The paper captures a preoccupation with 'being there' not as a dogmatic stricture nor a nostalgic retreat to a fantasy of a pre-digital reality, but rather as a hunch that physical presence - in learning, in design, in our making and experiencing of buildings and cities - is indeed, and undeniably, worth something. The studio teaching discussed in this paper actively explores this value in the making of architecture in relation to the city. Specifically, the paper focuses on (1) the specific model of the studio, (2) the developed mechanisms for studio collaboration and exchange, (3) the urban construct of the block as a framework, (4) the use of housing as design prompt, and (5) the working methods of the studio as reflections of core disciplinary knowledge.

\section{THE STUDIO}

The studio is a collaborative endeavor between two architecture schools, one American and one French, and it takes place in Paris. It includes approximately two dozen students from each school and it occurs annually for two months. Studio faculty are also from both schools and they work collaboratively on course preparation, teaching, and assessment of projects during this period. For American students, the studio is a part of a longer study-abroad experience, which includes a month of travel throughout Europe prior to the Paris studio (this travel portion is not coordinated with the studio). For French students the two months are a part of a longer studio, which begins approximately two weeks earlier and continues for another three weeks after. The studio culminates with a reunification of all the students and faculty for a weeklong workshop in the US.

At both institutions the studio is offered as an upper-level design course to both undergraduate and graduate students and although the majority of the students study architecture, they also bring some expertise and interest in the allied disciplines of interior, landscape, and urban design. Roughly 
one half of the students enrolled in the French program are participants of the Erasmus program and thus come from other institutions in Europe, Asia and Latin America, further amplifying to the diversity of perspectives that are present. Given such a population, and also considering the structure, schedule, and location of the studio, the aim was to develop a pedagogical framework that leverages such a specific set of circumstances in order to maximize learning outcomes. An important aspect of this learning, as the paper seeks to capture, is the relationship between architecture and the city.

\section{EXCHANGE AND COLLABORATION}

While many of the conditions that the studio had to engage are in and of themselves not unusual - study abroad, international collaboration, mixed academic backgrounds among them - their total sum required a specific approach to teaching that is to a significant degree unprecedented in architectural education. Yet these same conditions, as we observed, regularly find their equivalence in contemporary architectural practice. This, for example, includes the realities of working in an urban context with which one isn't entirely familiar; the mobility of labor a globalized market and the various durations of one's individual involvement on a particular project; and the diversity of knowledge, as well as a range of positions as to what constitutes core thinking and skills in architecture and its allied disciplines. As such, the studio is envisioned as a model for an architecture practice that is responsive to the realities of an increasingly globalized society, responding to the diversity of labor in architecture as well as to the complex needs of the city. In this way the studio deals with ways through which academia is able to respond to such established and emerging realities and as such transform some of conventional of studio teaching in architecture. Furthermore, the aim is to simulate, through pedagogy, a model of practice that is in this regard optimistic, equitable, and productive-a practice that values exchange, is profoundly collaborative, non-hierarchical, multi-disciplinary, grounded in specificity while remaining flexible and adaptive.

The tradition of architects' travels, going back to at least the Beaux Arts tradition, values disciplinary learning outside of one's own usual environment in order to observe and retain expertise embedded in exemplary works of architecture, grasp the unknown realities of places that one is perhaps only able to gain by being there, and bring back home whatever may be seen as valuable about such experiences. Such a model - though still in existence as the basis of many travel-based architecture programs - has certainly evolved over time and international collaborations among schools in different countries and continents is not uncommon. More often than not, however, such exchanges are limited in time, often resembling a form of tourism that prohibits the capacity for serious exchange between participants in different geographic locations. The studio recognizes the value of "being there" echoed by Peter Eisenman, both in terms of the time spent in the city and the participants spending a significant amount of time working together the same physical environment. For American students - but others as well - the problem of working in an unknown context (or rather, only somewhat known from previous mediated experiences) is seen as both an obstacle that one can try to overcome, but also an opportunity for contributing a fresh perspective to the design process. In this way, what it means to know a city, what it means to be there, and what it is about the city that one benefits from knowing are questions that are constantly explored in the studio, building upon the concerns one always while confronting the realities of architects' mobility as labor and the international scope of professional practice.

Students are organized in groups of six for the duration of the semester, each consisting of a cross-section of backgrounds, including an equitable mix of undergraduate and graduate students, American and French students (defined by institutional enrollment), Erasmus students, and architecture, interior design and urban design students. All the work is pursued collaboratively, without a pre-stated hierarchy or fixed tasks. All groups work on the same project at the scale of an urban block in Paris.

\section{BLOCK AS A FRAMEWORK}

The studio focuses on the architecture and urbanism of a Parisian block as is intimated by the studio title "Around the Block." Named by the French faculty whose use of the English term lacks self-consciousness, but that indeed intentionally suggests that one's ability to understand and deal with certain realities requires some experience of being on the ground - it is perhaps another, more playful, way of saying "being there."

The block in question is located in the 19th arrondissement of Paris bordering the suburb of Pantin. Its perimeter boundaries are defined by two busy roadways along the northern and western edges, a pedestrian street with a tramway along the eastern edge, and the Canal de l'Ourcq - built in the early 19th century as a shipping route and an urban water supply channel - as its southern boundary. Administratively the site forms the northeastern extension of the Bernard Tschumidesigned Parc de la Villette built in 1987, although it was not included as a part of the park's original 55.5 hectare design. Bisecting the site along the north-south axis is the Boulevard Peripheries, the major ring-road that surrounds the city along its perimeter. While the level of the Périphérique varies throughout - below grade, at grade, and above grade - the section captured by the site is elevated, providing an underside with some porosity between the two parts of the site. The primary architectural artifact on the site is a tannery, the Halle aux Cuirs - a two-story concrete shell of a building - constructed in the 1960s in relation to the complex of slaughterhouses, but soon thereafter made obsolete by their closure in the 1970s (thus clearing the ground for the 
Parc de la Villette), at the same time that the completion of the Périphérique would effectively cut it off from the rest of the city. Currently, the building on the site is used as a storage facility for a number of the cultural venues in the park and its grounds occasionally open up to the public for music festivals; a temporary structure serves as a circus school and the spaces under the elevated road are regularly appropriated by muralists. The block as such is not a part of a singular urban plan, but is rather a byproduct of a number of urbanistic decisions that have occurred over time. It is one of the last remaining sites in Paris open to future development whose destiny is not yet known.

In the context of the studio, the role of the block as a framework is twofold: urbanistic and pedagogic. The notion of the block, defined primarily by perimeter streets and its size in relation to the city and its buildings, serves as a device for framing - and thus identifying, collecting, and relating - otherwise seemingly disparate urban conditions. It also allows the site to become legible as an entity, provisionally seen as a whole when it is in fact a collection of fragments. The framework of the block in this way positions the site as neither a leftover nor a blank slate, but rather an entity with its own activities, qualities, and order. Yet this is not to reject the possibility of change, densification, or transformation; it is simply to acknowledge that its possible future isn't singular, based on a clear urban precedent, or entirely obvious.

Pedagogically, the framework of the block acts as boundary for sampling the city's complexity and as a device capable of mediating the relationship between architecture and urbanism. In this way the block is seen not as an isolating limitation, but rather as a connection between the site and its broader urban context. Throughout the semester students groups work on producing what we refer to an Allies Map, a relational drawing that shows the site's (present and projected) features as embedded within a set of crucial relationships across the city (infrastructure, constellations of institutions, public spaces, housing and so on). The map is not a precondition for design at the architectural scale, but rather a tool for iteratively testing the project's urbanistic agency. Furthermore, the studio project is by no means a master planning exercise, and pedagogically the framework of the block as an existing entity works to alleviate the impulse toward such an approach. Instead, the block is an active existing condition within which it is possible to test the consequences of new architectural interventions, whether they be additive, subtractive, adaptive, or a combination thereof. This is not to say that the design work is necessarily fragmentary in nature, or that the block isn't considered it its entirety, but rather that assigning a priori organization to the entire site is not a prerequisite for testing possibilities incrementally and at multiple scales. Given the specificity of the site, and the seemingly idiosyncratic combination of elements that it contains, the block is equally familiar and unknown to all the students regardless of background. As an open-ended condition the block necessitates multiple perspectives, approaches, and imaginations - and benefits from the insights gained on the ground, being there, around the block - serving as an inclusive framework appropriate to the nature of the studio.

\section{HOUSING AS A PROMPT}

The studio considers housing as fundamental to both the city and the practice of architecture. Beyond program and typology, social housing in France traditionally forms a core relationship between the discipline of architecture and the society that it serves. While the distinction between American and French approaches to housing design is not meant to be seen as binary, the comparison between student experiences on both sides of the educational experience is inevitable and productive. In Architecture of the City, Aldo Rossi argued that urban form is intrinsically connected to the problem of housing, making it, along with monuments, the primary element of the city. Originally written over 50 years ago, Rossi's book made a distinction between housing and houses; housing in a collective sense contributes to the city's permanence and evolves slowly, unlike individual houses which are impermanent and subject to faster change. Such assertions are as useful as they are helpful prompts for not only questioning the role of housing in the 21st century in global cities but also making room for the testing of a range of assumptions, both disciplinary and cultural. For example, what is the relationship between the temporary natures of the inhabitation of housing (workers, tourists, students, elderly) versus the relative permanence of architecture itself? How is social housing seen as transient in some contexts and stable in others?

How can we live here? The question is the first prompt for the students to consider relative to the site. The seemingly casual question is genuine - none of us teaching the studio are ever quite sure - but also devised to capture a set of considerations. First, what does it mean to live somewhere - in a hotel for two nights or a lifetime shared by three generations? Second, "here" - how does one get to speculate about the specificity of a place with limited first-hand knowledge? How does being there, for example, reveal that the constant hum of traffic along the Peripherique makes for a much more pleasant background sound than one could ever imagine by looking at the site on a map? And third, there is always the "how" which brings us to the realm of the discipline, the core of its knowledge, the methods. How does one, for example, determine the right density for the site, not on a given code, but in service of certain qualities of life? What programs are needed on the site to support housing and how much housing is required for the programs that make life there livable to survive? How can architecture contribute to mixité, the French term that stands for both diversity and mixed use? 

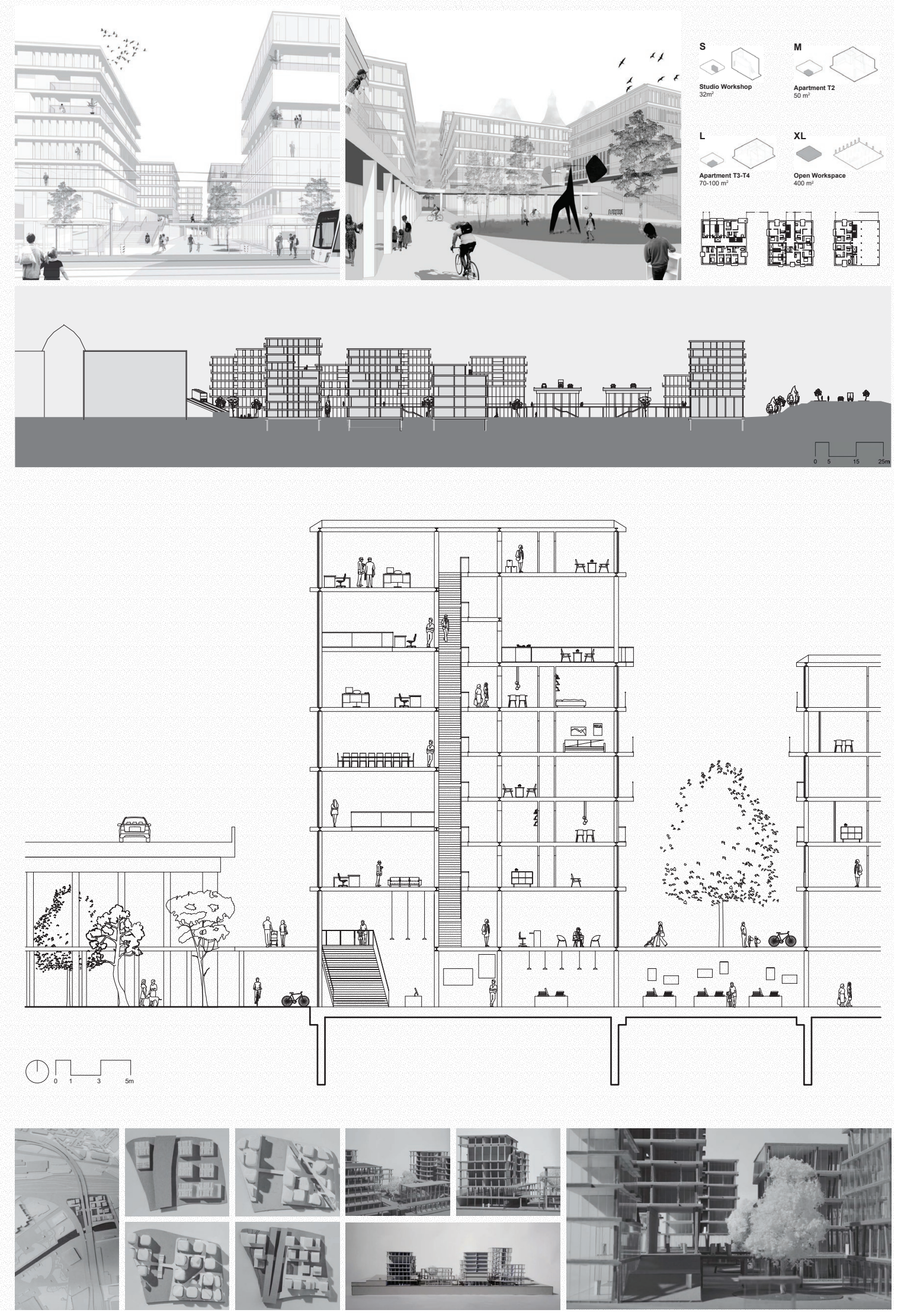

Figure 1. Paris to Pantin, a project by Aksel Borgen, Natalie Boverman, Maggie Gaudio, Lucas Monnereau, Théo Mulard and Caroline Stacey (2017). 
The given reference is 200 units of housing for the site, but the variety of units is open. Non-housing programs are developed by each team depending on their individual approach, though each year different secondary prompts are given. One year, the existing building on the same site had to be maintained, another year it was eliminated at the outset, but in both cases a cultural program of the same volume as the existing building was to be maintained. Live/work was introduced for one of the studios as both a housing type and as a way of conceptualizing the relationship between housing and places of production; culture/leisure served as a secondary axis that would relate the site to the park in some way.

\section{METHODS AND MOTIVES}

The studio encourages the conception and development of an architecture whose specificity does not come from its own image, but rather through the articulation of its capacities. Buildings are often most compelling during construction, at that moment then all the structure is built - the skeleton in concrete or steel, sometime timber - but none of the layers that would eventually give them their most obvious identity are yet added; sometimes it only gets worse for buildings from there on and one sometimes wishes that they could be returned to their simpler, more naked state. In this studio, we look at things as if with $\mathrm{x}$-ray vision, our modes of representation primarily registering the skeleton rather than the skin. It is an attempt to augment the impact that images have on architecture's identity throughout the process of design. By focusing on structure - loadbearing elements, floor slabs, circulation - that is, elements, that are not uncommonly figured out later on in the process, some things are made more explicit early on (such as scale, proportion, size), while others remain ambiguous (such as the precise boundaries between inside and outside, the definition of the building envelope, non-structural considerations of materiality). In other words, we place on hold design decisions that are best determined through images, and instead focus on physical modeling of architectural conditions primarily describable through structure. Eschewing standard practice, the exploration of structure is not limited to a single scale, but rather carries through at every scale of the projects, from that of the building detail to that of the site. This is not necessarily a matter of resolution - given the overall complexity and timing of the semester, the projects are typically still quite fragile in many ways - but rather of the overall attitude about design process, one for which multi-scalar investigation is central.

The scalar references, which are followed from day one are as follows: 1:100 for the scale of individual units, 1:200 for the aggregation of units at the scale of buildings, 1:500 at the scale of the site as a system, and 1:1000 for the scale of the city. The emphasis on scalar simultaneity, structure, and section serves to circumvent the convention - and the temptation - of resorting to 'master planning' as a precondition of architecture at the scale of buildings. On the other hand, the notion of the fragment and seen as temporal and at times temporary - conditions rather than necessarily finite outcomes.

There is a certain 'normcore' aspect to the representations that result from such methods. The understated, direct, plain - and seemingly generic - aesthetic qualities of the projects as they are presented can be misunderstood for promoting an architecture of the generic city. But on the contrary, the deadpan representations are another layer of articulating the necessity for 'being there' - not only resisting the notion that representations are proxies for real, lived experiences, but also that to 'be there' in the design process requires 'getting there' first - so there's no significant value (in this studio at least) in over-representing certain aspects of the architecture without really getting to design it first.

\section{CONCLUSION}

As the paper has described, the studio seeks to define a pedagogy for an architecture in the city that is post-spectacle and do so in ways that are contemporary and forward-thinking rather than regressive. Through a three-year studio cycle we have sought to articulate the value of "being there" in light of the many forces - labor, politics, technology, education etc. - that work to complicate what that means today. 